\title{
Study on MO Zi's Thoughts of Labor Division
}

Ziwei Peng ${ }^{1, a}$ and Shuang Peng, ${ }^{1,}$

\author{
${ }^{1}$ Business School, China West Normal University, Nanchong 637009, China \\ apengzw1996@126.com, bbjf1970@126.com
}

\begin{abstract}
This paper studied the purpose of Mozi's claim to labor division, the form of labor division and safeguard measures through using the literature method. The purpose of labor division is aimed at "improve the benefit of the world"; the labor division mainly include the labor division by gender, the labor division by industry, the labor division by production process and the labor division by brains and hands; Labor division efficiency can get protection through performance assessment that combine "strong to do", everything plays its role, focusing on productive labor knowledge and skills training and technology knowledge education, advocate similarity, advocate wisdom, law and morality, and the "cooperation and view" and "real name".
\end{abstract}

Keywords: MO Zi; Thoughts of labor division; Types of labor division; Safeguard measures for labor division

\section{墨子分工思想研究 \\ 彭紫微 ${ }^{1}$, 彭双 ${ }^{1}$ \\ (西华师范大学商学院, 四川 南充)}

摘要：运用文献资料法，研究了墨子主张分工的目的，分工的形式和分工保障措施。分工的目的是 “兴天下之利”; 分 工主要有性别分工、行业分工、生产过程分工和体脑分工; 分工效率通过 “强力从事”、各事其能、注重生产劳动知识与技 能培训和科技知识的教育、尚同、尚贤、法仪和 “合志功而观”与 “名实相符”的绩效考核予以保障。

关键词: 墨子; 分工思想; 分工形式; 分工效率保障措施

中图分类号: 0931 文献标志码：A

\section{引言}

墨子是一位伟大的思想家，他所创立的墨家学派在先秦时与儒家并称显学，《韩非子・显学》曰: “世 之显学, 儒墨也。儒之所至, 孔丘也。墨之所至, 墨翟也。” ${ }^{[1]}$ 墨子思想是中国传统思想库中的瑰宝之一, 它博大精深, 充满智慧。在先秦所有的思想家中, 墨子的社会分工学说最为全面、丰富、详细。这是墨子 思想中的精华, 是墨子留给后人的宝贵财富。

国内史学界一般认为, 继夏朝之后, 商周之际, 中国古代的农业和手下业有了大规模的分工, 体力劳 动和脑力劳动的分工也日益明显。其中青铜工具的出现，标志着生产力发展到了个新的阶段，它使农业、 手工业、水利工程等等, 都大大发展到了一个新水平 ${ }^{[2]}$ 。春秋战国时期, 不仅存在着封建统治者控制的主 要手工业部门, 如冶铁、煮盐、粮食加工、制造兵器和铸钱业, 以及为统治者服务的其他行业; 同时, 也 存在着独立的手工业者，他们有固定的劳动场所和来往的主顾，他们操着世代相传的技艺，经营自己的产 品或其他小商品。这一群体墨家称之为 “工肄之人”, 也是墨家成员之主体。墨子是手工业者出身, 熟悉 手工业里的不同行业、专业, 所以, 墨子这方面的分工学说比较细致。墨子的分工学说是当时社会生产发 展水平和政治状况的反映，在中国管理思想史上具有首创意义。 ${ }^{[3]}$

本文试图解读墨子的分工思想中分工的目的，分工的形式和分工效率的保障措施，从而发扬其思想中 
的具有积极意义的合理内核, 以弘扬中国传统管理文化、促进当今管理科学的发展。

\section{1 分工目的}

墨子学说的核心是 “义”，即 “天下之利”，其学说的基本内容 “尚贤、尚同、兼爱、非攻、节用、节 葬、天志、明鬼、非乐、非命” 都是围绕 “兴天下之利，除天下之害” 而服务，以实现 “使劳者得息，饥 者得食, 寒者得衣” (《尚贤下》) 和 “使老而无子者, 有所得终其寿; 连独无兄弟者, 有所杂于生人之间; 少失其父母者, 有所放依而长” (《兼爱中》) 的社会理想。如《尚同中》云: “故古者圣王明天、鬼之所欲, 而辟天、鬼之所憎, 以求兴天下之利, 除天下之害。”《兼爱中》开宗明义: “子墨子言曰: “仁人之所以为 事者, 必兴天下之利, 除去天下之害, 以此为事者也。”。《明鬼下》云: “今天下之王公大人、士君子, 实将欲求兴天下之利, 除天下之害, 故当鬼神之有与无之别, 以为将不可以不明察此者也。”

同理, 分工也是为 “兴天下之利”。墨子本人在《耕柱》篇云： “为义犹是也, 能谈辩者谈辩, 能说 书者说书, 能从事者从事, 然后义事成也”。这里的所谓 “义事”, 就是 “天下之利”。墨子认为只有通过 合理的社会分工，才能 “义事成”

\section{2 分工形式}

从墨子的著述来看，分工存在于国家治理、生产的方方面面，几乎无处不在。墨子著述的社会分工主 要有以下形式:

性别分工: 因为男女性别差异造成男女之间生理能力上的不同, 男子力大耐劳, 而妇女心细手巧。墨 子在《非乐上》中说: “农夫蚤出暮入, 耕稼树艺, 多聚叔粟, 此其分事也。妇人夙兴夜蒋, 纺绩织纴, 多治麻丝葛绪, 捆布縿, 此其分事也。” 墨子表达了 “男主外、女主内” 的性别分工思想, 男子从事户外 劳动强度大的工作（如耕稼树艺）和女子从事劳动强度小的户内工作（如纺绩织经）是各自分内之事。

行业分工：墨子著作中把社会分为王公大人、士君子、农夫与农妇、百工（即手工业者）和商人五大 群体。彼此的 “分事” (即工作职责) 是不同的。王公大人的 “分事” 是 “蚤朝晏退, 听狱治政” (《非乐 上》); 士君子的 “分事” 是 “股肱之力, 亶其思虑之智，内治官府，外收玫关市、山林、泽梁之利，以实 仓廪府库。”农夫的 “分事” 是 “蚤出夜入，耕稼树艺，多聚叔粟，”，农妇的 “分事” 是 “夙兴夜宊，纺 绩织纴, 多治麻丝葛绪, 捆布縿”。百工的 “分事” 是 “轮车葷鞄, 陶冶梓匠。”(《节用中》) 或 “修舟车, 为器血” (《节葬下》)。关于商人的 “分事”, 他说 “商人之四方, 市贾信徒, 虽有关梁之难, 盗贼之危, 必为之。”(《贵义》)。

生产过程分工：墨子以筑墙为例, 强调了在具体的生产过程中, 由于生产技术的复杂性, 应尽可能地 按照生产劳动过程的不同阶段进行分工, 这有利于技术的熟练掌握, 劳动效率的提高。《耕柱》篇云: “譬 若筑墙然, 能筑者筑, 能实壤者实壤, 能欣者欣, 然后墙成也。” 墨子在此指出了分工的必要性与合理性 在于提高生产的效率。

体脑分工:《非乐上》云: “王公大人，蚤朝晏退，听狱治政，此其分事也。士君子竭股肱之力，亶其 思虑之智, 内治官府，外收玫关市、山林、泽梁之利，以实仓廪府库，此其分事也。农夫蚤出暮入，耕稼 树艺，多聚叔粟，此其分事也。妇人夙兴夜蒋，纺绩织纴，多治麻丝葛绪捆布縿，此其分事也。” 墨子的 意思是王公大人和士君子从事的是脑力劳动, 即处理政事、管理社会, 而农夫和妇人的工作是体力劳动, 即耕种、纺织, 创造物质财富。墨子在《耕柱》中说: “能谈辩者谈辩, 能说书者说书, 能从事者从事, 
然后义事成也。” 在这里, 谈辩和说书属脑力劳动, “从事” 属体力劳动。墨子充分认识到脑力劳动价值大 于体力劳动的价值。《鲁问》记载了墨子与吴虑辩论自耕与教耕哪个效果更大的问题。墨子认为, 自己亲 自耕田、纺织、或上战场打仗, 最多也不过比得上一农夫、妇人或士兵, 但把这些东西分给天下人, 不能 使天下的饥者饱食, 不能使天下寒者得暖, 抵不过三军。他认为先诵习先王之道, 细察其文辞, 再上以游 说王公大人, 次以游说平民徒步之士, 而王公大人用其言论, 国家必治; 匹夫徒步之士用其言论, 行为必 得修正。墨子肯定了脑力劳动的作用大于单纯的体力劳动, 主张有识之人去教导和帮助没有知识的人。

\section{3 分工效率保证措施}

强调 “强力从事” (即努力工作) : 首先, 墨子认为努力工作是人与动物的区别之一。《非乐上》中说

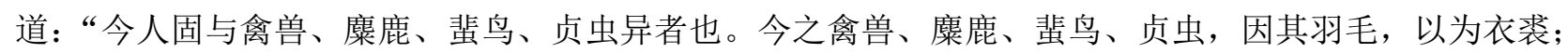
因其蹄虫, 以为绔屡; 因其水草, 以为饮食。故唯使雄不耕稼树艺, 雌亦不纺绩织纴, 衣食之财, 固已具 矣。今人与此异者也, 赖其力者生, 不赖其力者不生。君子不强听治, 即刑政乱; 贱人不强从事, 即财用 不足。” 其次, 他认为努力劳动不仅决定个人的贫富、贵贱和荣辱, 还决定国家安宁与否。《非命下》云: “......强必贵, 不强必贱; 强必荣, 不强必辱。……强必富, 不强必贫; 强必饱, 不强必饥。……强必富, 不强必贫; 强必暖, 不强必寒。故不敢急倦。……强必治, 不强必乱; 强必宁, 不强必危。故不敢急倦。”

“各事其能”：墨子认为人才应该使其 “各从事其所能”，即应该各尽所能，用其所长。由于每个人的 能力、性格、经历差异较大, 而各种不同的工作需要不同才能的人, 所以在用人时一定要合理分工, 各尽 所能, 用人所长, 使每个人在最合适的岗位上做出最大的成绩。《节用中》云: “凡天下群百工, 轮车鞼匏, 陶冶梓匠, 使各从事其所能。”《耕柱》篇云: “譬若筑墙然, 能筑者筑, 能实壤者实壤, 能欣者欣, 然后 墙成也。为义犹是也, 能谈辩者谈辩, 能说书者说书, 能从事者从事, 然后义事成也。” 《杂守》云: “有 㭸人, 有利人, 有恶人, 有善人, 有长人, 有谋士, 有勇士, 有巧士, 有使士, 有内人者, 外人者, 有善 人者, 有善门人者, 守必察其所以然者, 应名乃内之。《尚贤中》云: “故可使治国者使治国, 可使长官 者使长官, 可使治邑者治邑。” (可以让他治国的, 就让他治国; 可以让他居官的, 就让他居官; 可以让他 治县的, 就让他治县。)

注重生产劳动知识与技能培训和科技知识的教育: 墨子及其门徒既是生产者阶层又是有文化的士阶 层。双重身份使他们有条件且有能力将生产劳动和教育活动相结合。他们不但直接参与生产劳动, 练就高 超技艺, 而且从生产实践中探索有价值的劳动经验, 并将这些经验知识与技能作为教学内容, 代代相传, 且明确提出 “与其劳者获其实” 的劳动观念教育。墨子极为重视生产技能和自然科学技术的教育, 目的是 要把 “农与工肆之人” 培养成为 “各从事其所能” 的 “兼士”。较之孔子的 “六艺” 教育和其鄙视生产劳 动、轻视科学知识的观点, 墨子的劳动观念学说无疑是对传统文化的一大贡献。在 “不学礼, 无以立” 的 社会背景下别具一格, 他创造性地把在生产实践中获得的自然知识与科技经验融入教育体系之中, 增加了 许多与生产实践相结合的实学内容。墨子在科学技术上的深入研究和教育方面的卓越贡献, 丰富拓展了传 统文化, 在中国教育史上写下了壮丽的篇章。“在历史上第一次把知识分子和劳动生产实践相结合, 知识 与生产相结合。” [4] 墨子的科技工艺教育思想是中国古代教育史上璀嗓的火花, 却没有在社会发展中得 到应有的发扬光大。这不能不说是一种遗憾, “中国墨学中绝, 故以后科学永不发展”。[5]

尚同：所谓 “尚同” 即 “一同天下之义”, “一同其国之义” (《尚同中》)，即保持国家的政治、思想、 
文化、经济、法制等方面的高度统一。只有当组织的目标获得大家的认可，成员才可能心往一想，劲往一 处使。墨子的尚同绝不是专制，它以尚贤（推举天下的贤能者为政长）和下情上达为前提。他试图建立一 种下情上报制度，要求所有的人都必须向上报告下情，各级官吏更不能匿情不报。《尚同上》篇云: “天子 发政于天下之百姓, 言曰: “闻善而不善, 皆以告其上。……有过则规谏之, 下有善则傍荐之。…… 里长发政里之百姓, 言曰: ‘闻善而不善, 必以告其乡长。…… 乡长发政乡之百姓, 言曰: ‘闻善而不善 者, 必以告国君。……国君发政国之百姓, 言曰: ‘闻善而不善, 必以告天子。”

尚贤：墨子在《亲士》篇明确提出人才决定国家命运的观点：“入国而不存其士，则亡国矣。见贤而 不急, 则缓其君矣。非贤无急, 非士无与虑国。缓贤忘士, 而能以其国存者, 未曾有也。” 他认为, 贤士 能使国家 “得富、得众、得治”。墨子说: “故士者所以为辅相承嗣也。故得士则谋不困, 体不劳, 名立而 功成, 美章而恶不生, 则由得士也。” 国家的贤人多了, 恶人、庸人就相对减少。要使社会上的贤人多起 来, 就要使人人都有争做贤人的精神风貌, 即孔子所说的 “见贤思齐, 见不贤而内自省也”。人人都自觉 地以有德、有智、有能之人为楷模, 努力学习、追赶和超越。墨子为了实现尚贤使能的目标, 提出了 “有 能则举之、无能则下之，举公义，辟私怨”(《尚贤上》) 这一非常重要的选拔贤才的原则。

法仪：墨子认为做什么事都有一定规则。《法仪》篇云: “天下从事者，不可以无法仪; 无法仪而其事 能成者, 无有也。虽至士之为将相者, 皆有法, 虽至百工从事者, 亦皆有法。百工为方以矩, 为圆以规, 直以绳, 正以县。无巧工、不巧工, 皆以此五者为法。巧者能中之, 不巧者虽不能中, 放依以从事, 犹逾 己。故百工从事, 皆有法所度。今大者治天下, 其次治大国, 而无法所度, 此不若百工辩也。” 他主张不 论百工还是将相都要按法度办事。

进行 “合志功而观” 和 “名实相符” 的绩效考核：墨子明确地指出 “合其志功而观”, 就是把动机与 效果结合起来对人的行为进行评价, 不能偏废任何一方, 否则, 就不能对人们的行为做出恰如其分的评价。 《鲁问》篇记载: “鲁君谓子墨子曰: ‘我有二子, 一人者好学, 一人者好分人财, 孰以为太子而可? ’ 子 墨子曰: “未可知也。或所为赏与为是也。钓者之恭, 非为鱼赐也; 饵鼠以虫, 非爱之也。吾愿主君之合 其志功而观焉。” ”所谓名实相符, 就是根据事物的实际情况, 给予相应的名称。《经说上》云: “所以谓, 名也。所谓, 实也。名实耦, 合也。” 那么在考察人时不要被表面现象所迷惑。墨子认为在服饰与行为之 间, 服饰并不重要, 重要的是行为。《公孟》载, 公孟子戴着礼帽, 腰间插着笏, 穿着儒者的服饰, 前来 会见墨子, 说: “君子穿戴一定的服饰, 然后有一定的作为呢？还是有一定的作为，再穿戴一定的服饰？” 墨子说 “行不在服”, 并举例说, 齐桓公、晋文公、楚庄王、越王勾四位国君的服饰不同但国家得到很好 治理, 因此 “行之不在服也。”

\section{结论}

墨子的分工思想在当时比较完善。分工的目的是 “兴天下之利” ; 分工形式主要包括性别分工、行业 分工、生产过程分工和体脑分工; 分工效率的保证措施包括 “强力从事”、各事其能、注重生产劳动知识 与技能培训和科技知识的教育、尚同、尚贤、法仪和 “合志功而观” 与 “名实相符” 的绩效考核。

\section{参考文献:}

[1] 陈奇鄭. 韩非子新校注 [M]. 上海: 上海古籍出版社, 2000.

[2] 李少白编: 《科学技术史》, 华中工学院出版社, 1984 年, 第 63 65 页。

[3] 史向前, 陆建华. 墨子外传、墨子百问, 安徽人民出版社, 1996。 
[4] 张瑞璠, 陈超群: 《中国教育哲学史》(第 1 卷), 济南: 山东教育出版社, 2000 年: 127, 138 。

[5] 赵伯庄: 《高职院校社会实践教学状况调查与分析》, 职业技术教育 (教科版), 2002 年。.

\section{References:}

[1] Chen Qiyou. Han Feizi new school note [M]. Shanghai: Shanghai Ancient Books Publishing House, 2000.

[2] Li Shaobai: "History of Science and Technology", Huazhong Institute of Technology Press, 1984, 63-65.

[3] Shi Xiangqian, Lu Jianhua. Mozi rumor, Mozi one hundred Question, Anhui People's Publishing Press, 1996.

[4] Zhang Ruifan, Chen Chaoqun: "History of Chinese Philosophy of Education" (Volume 1), Jinan: Shandong Education Press, 2000: 127, 138.

[5] Zhao Bozhuang: "Vocational college social practice teaching situation survey and analysis", Vocational and Technical Education (teaching edition), 2002. 